\title{
Mehr Weitsicht in der Drogenpolitik! Wann endlich?
}

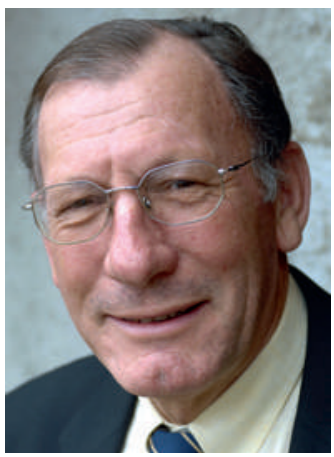

Jean Martin
In meinem Berufsleben, in dem ich oft mit dem Thema Drogensucht konfrontiert war, verlor ich allmählich alle Illusionen angesichts eines gesellschaftlichen Diskurses, der - hier und anderswo - ausserstande war, praktische Erfahrungen zu berücksichtigen und falsche, auf ideologischen Vorurteilen basierende Doktrinen ausser Acht zu lassen. Der Entscheid der eidgenössischen Räte, Cannabis-Raucher nicht mehr vor den Kadi zu zitieren, sondern nur mit einer Ordnungsbusse zu belegen, geht in die richtige Richtung, ist aber ein kleiner Schritt angesichts der notwendigen grossen Veränderungen.

Natürlich handelt es sich um ein weltweites Phänomen. Niemand, der einen einigermassen ernstzunehmenden Standpunkt vertritt, bestreitet heute das Scheitern des damals von Nixon eingeleiteten War on Drugs und der Repressionspolitik der damaligen Hardliner (die wie die Prohibition der 30er Jahre vor allem mafiösen Strukturen zum Leben verhalf). Polizeiliche Entscheidungsträger in den USA haben das Scheitern jeglicher Repressionspolitik zugegeben.

Beim Amerika-Gipfel im kolumbianischen Cartagena im April war die Thematik sehr präsent, auch wenn die US-Opposition offizielle Schritte blockiert. Dennoch: «Die Überzeugung, nach der die - wenngleich ineffiziente - Antidrogenpolitik nicht modifiziert werden kann, ist erschüttert.» [1]. Staatschefs jeglicher Couleur stellen sich gegen «die Illusion der Repression». Während Mexiko von seinem nördlichen Nachbarn gezwungen wird, sich an der Repression zu beteiligen, suchte Calderon, der (konservative) Präsident des Landes, Marktalternativen zur Prohibition.

Die «Karawane des Friedens» startete am 12. August dieses Jahres in San Diego und wird am 12. September in Washington ankommen [2]. Sie vereinigt Hunderte von Verbänden von Opfern aus dem Krieg gegen den Drogenhandel. Seit 2006 forderte dieser Krieg in Mexiko schätzungsweise 70000 Menschenleben (mindestens 10000 mehr als US-Tote im Vietnamkrieg!). Der Unmut richtet sich vor allem gegen die Tatsache, dass die USA die grössten Konsumenten mexikanischer Drogen sind und der grösste Exporteur der von Drogenkartellen benutzten Waffen. Ein kompletter Politikwandel ist unabdingbar. Ein grosses Hindernis besteht inzwischen darin, dass dieser Krieg weltweit Broterwerb für Tausende, wenn nicht gar Millionen von «Guten» (inkl. deren Chefs, die von der generellen Korruption profitieren) und «Bösen» (Händler) ist!

Hier gilt es, den Hut zu ziehen vor Ruth Dreifuss, die mit Weitsicht an der Global Commission on Drug
Policy teilnimmt, deren Vorsitz der ehemalige brasilianische Präsident Cardoso innehat und deren weitere Teilnehmer u.a. Kofi Annan, Louise Arbour, Richard Branson und ein ehemaliger US Staatssekretär sind. Die Kommission hat sich in einem Bericht im Jahr 2011 [3] deutlich artikuliert. Angesichts der bisherigen Enttäuschungen gilt es nun, Formen der kontrollierten Legalisierung und Besteuerung zu finden, die u.a. dazu beitragen, die Macht der mafiösen Strukturen zu brechen. Der in den Niederlanden gewählte Ansatz der «Coffee Shops» trifft in der Tat immer wieder auf Schwierigkeiten, doch der unerwünschte Tourismus kommt aus den benachbarten Prohibitionsländern. In Portugal etwa wurden in den zehn Jahren seit der Entkriminalisierung nicht mehr Drogen konsumiert.

Wie Ruth Dreifuss am 19. Juli auf Radio Suisse Romande erklärte, ist es nicht möglich, alles von jetzt auf gleich zu ändern, wichtig ist jedoch, die notwendige Kursänderung zu veranlassen! Zumindest müssen die durch die Beharrung auf Repressionsstrategien bewirkten Negativaspekte (bei Gesundheit und Kriminalität) anerkannt werden.

Positiv lässt sich vermerken, dass unser Land durch die gute Viersäulenpolitik - sie schränkt vor allem die gesundheitlichen Schäden (Aids, Hepatitis) [4] ein - trotz anachronistischer Prohibitionsstrategie wertvolle Beiträge leistet. Ausserdem werben in der Eidgenössischen Kommission für Drogenfragen Persönlichkeiten mit Weitblick für eine sachbezogene Haltung, die den grossen Ähnlichkeiten im Missbrauch aller Suchtmittel Rechnung trägt [5]. So ist eine jüngste Veröffentlichung zu begrüssen, die nach einer echten «Gesellschaftspolitik» verlangt [6].

Der kolumbianische Präsident Santos zum Scheitern dessen, was bislang in die Tat umgesetzt wurde: «Es ist wie beim Heimvelo, man tritt in die Pedale und kommt nicht vom Fleck.» Dies entspricht auch den wiederholt zum Ausdruck gebrachten Empfindungen des Autors und ehemaligen Kantonsarztes, der die Problematik des Drogenhandels seit 1960-1970, als er in Südamerika und in den USA arbeitete, verfolgt. Bei unseren Politikern müssen die Scheuklappen fallen. Weil ein Teil der Öffentlichkeit der Illusion des Kampfes verhaftet bleibt, wünscht man ihnen die erforderliche Prise «Zivilcourage», um einen Richtungswandel vorzunehmen.

Jean Martin, ehemaliger Kantonsarzt und Redaktionsmitglied 